\title{
Comparison of Clinical and Angiographic Results in COVID-19- Positive and -Negative Patients Undergoing Primary Coronary Intervention due to ST-Elevation Myocardial Infarction
}

\author{
Zeynep Yapan Emren ${ }^{1}$, Rahman Bilal Gediz², Fatih Levent ${ }^{3}$, Sadık Volkan Emren", Oktay Şenöz ${ }^{1}$ \\ ORCID: \\ Zeynep Yapan Emren: https://orcid.org/0000-0002-5508-9474 \\ Rahman Bilal Gediz: https://orcid.org/0000-0002-7279-6373 \\ Fatih Levent: https://orcid.org/0000-0002-7160-4050 \\ Sadık Volkan Emren: https://orcid.org/0000-0002-7652-1123 \\ Oktay Şenöz: https://orcid.org/0000-0002-3847-7598
}

${ }^{1}$ Department of Cardiology, Bakırçay University Çiğli Training and Education Hospital, ${ }^{2}$ Department of Cardiology, Manisa City Hospital, ${ }^{4}$ Department of Cardiology, Izmir Katip Celebi University School of Medicine Izmir, Izmir, ${ }^{3}$ Department of Cardiology, Bursa Yüksek Intisas Training and Research Hospital, Bursa, Turkey

\section{Abstract}

Introduction: Although coronavirus disease-19 (COVID-19) primarily causes respiratory system infection, it may cause thrombosis in the cardiovascular system. In this regard, we aimed to compare cardiovascular outcomes between COVID-19-positive and-negative patients with ST-segment elevation myocardial infarction (STEMI). Methods: This was a retrospective study that consecutively included 96 COVID - and 36 COVID+ patients with STEMI. Clinical, laboratory, and angiographic characteristics were obtained from hospital records, and these variables were compared between groups. Results: COVID-19 patients with STEMI had higher Killip score $(3-4)(78$ vs. $30, P<0.001)$ and mortality $(42 \%$ vs. $21 \%, P=0.017)$. Among COVID-19 patients with STEMI, $83 \%$ had lung infiltration. According to the angiographic findings, COVID-19 patients had a shorter door to balloon time (35 \pm 20 vs. $49 \pm 17, P=0.013$ ), glycoprotein IIb/IIIa antagonist use, and shorter door to balloon time. Conclusion: COVID-19 patients with STEMI had a higher rate of cardiogenic shock and mortality.

Keywords: Acute coronary syndrome, coagulopathy, coronavirus disease-19, severe acute respiratory system syndrome coronavirus-2, ST-segment elevation myocardial infarction

\section{INTRODUCTION}

Coronavirus-2019 disease caused by severe acute respiratory system syndrome coronavirus 2 (SARS-CoV-2) has been accepted as a pandemic by the World Health Organization. Although coronavirus disease-19 (COVID-19) primarily affects the respiratory system, it may also lead to thrombotic complications in the cardiovascular system. ${ }^{[1]}$ It is believed that COVID-19associated thrombosis may be due to increased inflammation, over-activation of platelets, and endothelial damage. ${ }^{[2]}$

It is no denying that thrombosis plays a major role in the pathophysiology of ST-segment elevation myocardial

Received: 02-05-2021 Revised: 15-06-2021 Accepted: 12-07-2021

Published Online: 25-09-2021

\begin{tabular}{|l|l|}
\hline \multicolumn{3}{|c|}{ Access this article online } \\
\hline Quick Response Code: & Website: \\
& \\
http://www.ijcva.com
\end{tabular}

infarction (STEMI). The state-of-the-art treatment for STEMI is primary angioplasty, which improves the cardiovascular outcomes in or out of the hospital treatment period. ${ }^{[3]}$

COVID-19 patients may be disadvantageous concerning the treatment of cardiovascular diseases. During the COVID-19 pandemic, it is possible that SARS-CoV-2-infected patients, especially those with STEMI, may refrain from hospital treatment facilities. Besides, given the tendency of thrombosis

Address for correspondence: Dr. Zeynep Yapan Emren, 54, 8019/11 Atasehir Street APT 8/4, Çiğli, Izmir, 35620, Turkey. E-mail: zeynepyapan@hotmail.com

This is an open access journal, and articles are distributed under the terms of the Creative Commons Attribution-NonCommercial-ShareAlike 4.0 License, which allows others to remix, tweak, and build upon the work non-commercially, as long as appropriate credit is given and the new creations are licensed under the identical terms.

For reprints contact: WKHLRPMedknow_reprints@wolterskluwer.com

How to cite this article: Emren ZY, Gediz RB, Levent F, Emren SV, Şenöz O. Comparison of clinical and angiographic results in COVID-19positive and -negative patients undergoing primary coronary intervention due to ST-elevation myocardial infarction. Int J Cardiovasc Acad 2021;7:78-82. 


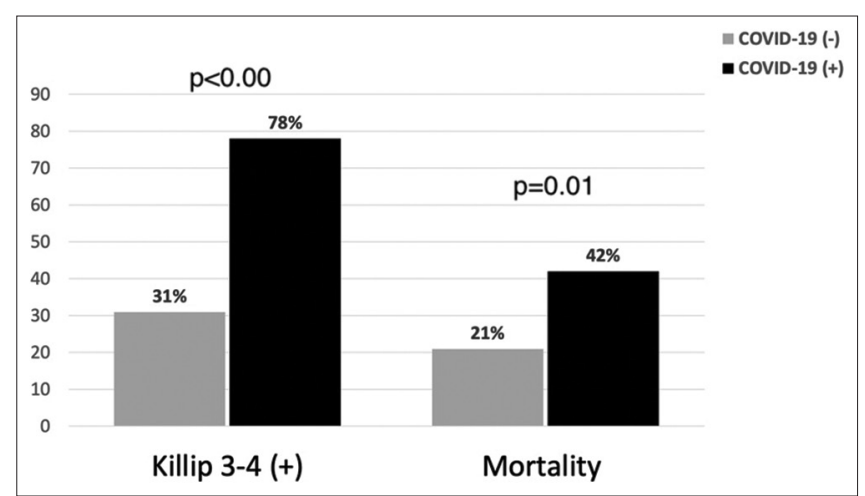

Figure 1: Mortality and High Killip score (3-4) of ST segment elevation myocardial. Elevation patients with or not COVID-19

in COVID-19, those with STEMI may be overcomplicated. Therefore, we aimed to compare in-hospital cardiovascular outcomes between STEMI patients with or without COVID-19.

\section{Methods}

This was a multicenter retrospective study that consecutively included patients with STEMI who were hospitalized between December 2020 and March 2021. Ethical approval (2021-GOKAE-0076) and inform consent from patients were obtained. The study was consistent with the Declaration of Helsinki.

During the pandemic, all the patients who were admitted to the emergency department underwent a polymerase chain reaction (PCR) test for COVID-19. Those patients with a diagnosis of COVID-19 were investigated for the severity of pneumonia with computed chest tomography. COVID-19 treatment was arranged by an infectious disease specialist.

Patients over 18 years diagnosed with STEMI who underwent primary angioplasty were included. Those with non-STEMI, unstable angina pectoris, and stable angina and those who were treated with thrombolytic therapy were excluded.

The patient's symptoms, clinical status, vital signs, demographic and clinical variables, imaging results, and angiographic outcomes were obtained from hospital records. Laboratory findings were as follows: troponin, hemogram, D-dimer, ferritin, creatinine, and C-reactive protein. Besides, STEMI was defined as ST elevation of $1 \mathrm{~mm}$ in consecutive leads except for V2-V3 for which at least 2 and $2.5 \mathrm{~mm} \mathrm{ST}$ elevation in man $<40$ and $\geq 40$ years old, respectively, or $1.5 \mathrm{~mm}$ ST elevation in women. For definition isolated posterior myocardial infarction (MI), $0.5 \mathrm{~mm} \mathrm{ST}$ elevation had to be present in the posterior chest wall leads. New occurrence of left bundle branch block in the state of myocardial ischemia was also accepted STEMI. ${ }^{[4]}$ Interventional strategy and medical treatment were at the discretion of the operator. Localization of MI, door to balloon time, culprit artery, glycoprotein (GP) IIb/IIIa treatment, thrombus aspiration catheter usage, thrombolysis in MI (TIMI) score, thrombus grade, and myocardial blush grade (MBG) were noted. ${ }^{[5-8]}$
Hypertension was present if the patient was on hypertension treatment or newly diagnosed hypertension as the consecutive blood measurement over 140/90 $\mathrm{mmHg} .{ }^{[9]}$ If the patient was on diabetes treatment or fasting blood glucose over $126 \mathrm{mg} /$ $\mathrm{dl}$ or $\mathrm{HgAlc}$ level over $6.5 \mathrm{~g} / \mathrm{dl}$, it was considered as diabetes mellitus (DM). ${ }^{[10]}$ Dyslipidemia was defined if the patient was on lipid treatment or had a high level of cholesterol according to cardiovascular risk score. ${ }^{[11]}$ Chronic renal failure was defined as the rate of glomerular filtration rate was lower than $60 \mathrm{ml} /$ $\mathrm{min} / 1.73 \mathrm{~m}^{2}$ lasting more than 3 months. ${ }^{[12]}$

\section{Ethical statement}

Ethical approval (2021-GOKAE-0076) and inform consent from patients were obtained. The study was consistent with the Declaration of Helsinki.

\section{Statistical analysis}

Statistical analyses were conducted using SPSS software version 23.0 (Armonk, NY: IBM Corp.). Variables were analyzed using visual and analytical methods to determine normal distribution. Continuous and categorical variables were expressed as mean and standard deviation and percentages, respectively. An independent $t$-test was used to compare between groups. A two-sided $P<0.05$ was considered statistically significant.

\section{RESULTS}

The mean age of the patients was $61 \pm 12$ years and $34(25 \%)$ were female. Table 1 demonstrates the baseline characteristics of patients. Regarding cardiovascular risk factors, hypertension and DM were more common in COVID-19 patients. In accordance with the respiratory system infection, COVID-19 patients had a higher rate of dyspnea, pneumonia, white blood cells count (WBC), ferritin, D-dimer value, and fewer lymphocytes, whereas lack of chest pain was more common in COVID-19 patients.

According to the clinical presentation, COVID-19 patients had the lower door to balloon time, higher rate of shock, and anterior MI. Although thrombus burden, basal TIMI grade was not different between patients, GP IIb/IIIa antagonists and thrombus aspiration catheter were more commonly used in COVID-19 patients [Table 2]. Although angiographic success such as post-PCI TIMI and MBG grade was not different, the rate of mortality and shock were higher in COVID-19 patients [Figure 1].

\section{Discussion}

Since the concern of catheter laboratories being infected with Sars Cov-2 at the start of the COVID-19 pandemic. Some authorities advocated thrombolytic therapy over primary PCI ${ }^{[13]}$ Moreover, there is a lack of data on the treatment and outcomes of COVID-19-positive STEMI patients. Initial studies demonstrated that a limited number of patients underwent PCI. ${ }^{[14]}$

In this retrospective observational study, we investigated the treatment and outcome difference in STEMI patients with 


\begin{tabular}{|c|c|c|c|}
\hline & COVID-19 (-) (n=96), $n(\%)$ & COVID-19 (+) (n=36), $n(\%)$ & $P$ \\
\hline Gender (female) & $24(24)$ & $10(28)$ & 0.676 \\
\hline Age (years) & $60 \pm 13$ & $64 \pm 10$ & 0.142 \\
\hline Hypertension & $42(42)$ & $25(69)$ & 0.005 \\
\hline Diabetes mellitus & $27(27)$ & $18(50)$ & 0.013 \\
\hline Dyslipidemia & $27(27)$ & $14(39)$ & 0.194 \\
\hline Chronic renal failure & $9(9)$ & $6(17)$ & 0.215 \\
\hline Smoking & $66(67)$ & $20(56)$ & 0.235 \\
\hline Prior PCI & $15(15)$ & $5(14)$ & 0.855 \\
\hline Prior CABG & 0 & $3(8)$ & 0.004 \\
\hline Chest pain & $96(100)$ & $32(89)$ & 0.001 \\
\hline Dyspnea & $36(36)$ & $24(67)$ & 0.002 \\
\hline Pneumonia & $9(9)$ & $30(83)$ & $<0.001$ \\
\hline \multicolumn{4}{|l|}{ MI localization } \\
\hline Anterior or anterolateral MI & $57(58)$ & $12(33)$ & 0.043 \\
\hline Lateral MI & $3(3)$ & $4(11)$ & 0.061 \\
\hline Inferior, posterior, or inferolateral MI & $39(39)$ & $20(56)$ & 0.124 \\
\hline Cardiopulmonary resuscitation & $15(15)$ & $2(6)$ & 0.137 \\
\hline Intubation & $9(9)$ & $7(19)$ & 0.100 \\
\hline LVEF & $41 \pm 11$ & $42 \pm 9$ & 0.512 \\
\hline \multicolumn{4}{|l|}{ Laboratory parameters } \\
\hline Troponin & $2005 \pm 1745$ & $2062 \pm 5570$ & 0.954 \\
\hline WBC & $10.023 \pm 8058$ & $1368 \pm 3804$ & $<0.001$ \\
\hline Hemoglobin & $13 \pm 2.1$ & $15 \pm 17$ & 0.489 \\
\hline Lymphocyte & $2761 \pm 2355$ & $1500 \pm 1079$ & 0.005 \\
\hline D-dimer & $46 \pm 136$ & $644 \pm 959$ & 0.001 \\
\hline Ferritin & $194 \pm 223$ & $828 \pm 772$ & $<0.001$ \\
\hline Creatinine & $1.2 \pm 0.9$ & $6.1 \pm 27.4$ & 0.301 \\
\hline CRP & $60 \pm 70$ & $84 \pm 79$ & 0.189 \\
\hline Door to balloon time & $49 \pm 17$ & $35 \pm 20$ & 0.003 \\
\hline \multicolumn{4}{|l|}{ Killip class } \\
\hline $1-2$ & $69(69)$ & $8(23)$ & $<0.001$ \\
\hline $3-4$ & $30(30)$ & $28(78)$ & $<0.001$ \\
\hline Mortality & $21(21)$ & $15(42)$ & 0.017 \\
\hline
\end{tabular}

CABG: Coronary artery bypass grafting, CRP: C-reactive protein, MI: Myocardial infarction, LVEF: Left ventricular ejection fraction, PCI: Percutaneous coronary intervention, WBC: White blood count, COVID-19: Coronavirus disease-19

or without COVID-19. According to this study the rate of mortality and cardiogenic shock, were higher in COVID-19 patients compared to COVID-19-negative patients.

The mortality rate in this study was higher than landmark STEMI trials in both COVID-19-positive and -negative patients. Previous studies showed that COVID-19 infection was associated with higher mortality and poorer outcomes in STEMI ${ }^{[14,15]}$ At the beginning of the pandemic, COVID STEMI patients had a fourfold risk of mortality. Besides; heart failure, stent thrombosis, cardiogenic shock development after PCI was higher in COVID-19 STEMI patients than non-COVID-19 STEMI patients. ${ }^{[16]}$

SARS-CoV-2 virus infection may increase thrombosis in COVID-19 patients leading to platelet activation and endothelial dysfunction. Besides, systemic inflammatory response may cause hemostatic and thrombotic activation. ${ }^{[17]}$ Therefore, anti-aggregant and antithrombotic treatment take part in COVID-19 infection. Acute MI development on the top of COVID-19 may increase the burden of thrombosis and cardiovascular complications. In this regard, some factors might explain the higher mortality rate in this study in COVID-19 patients. Coagulation markers such as high D-dimer and inflammatory markers such as high WBC and low lymphocytes were shown to be correlated with disease severity in COVID-19. These findings were consistent with the results of our study. In our study angiographic introcoronary thrombus grade was not different However, Choudry et al. showed that COVID-positive STEMI patients had higher thrombus grade, multivessel thrombosis, and stent thrombosis. ${ }^{[15]}$

Conventional cardiovascular risk factors such as hypertension and DM were more often present in COVID-19 patients. These risk factors were known to increase mortality in coronary artery disease. Furthermore, hypertension and DM had a link to mortality in COVID-19 infection. ${ }^{[18]}$ Furthermore, another predictor for mortality was pneumonia. In our study, majority of the COVID patients with STEMI had pneumonia. 


\begin{tabular}{|c|c|c|c|}
\hline & COVID-19 (-) (n=96), $n$ (\%) & COVID-19 (+) $(n=36), n(\%)$ & $P$ \\
\hline Door to balloon time & $49 \pm 17$ & $35 \pm 20$ & 0.003 \\
\hline \multicolumn{4}{|l|}{ Culprit artery } \\
\hline LAD & $57(58)$ & $14(39)$ & 0.054 \\
\hline $\mathrm{CX}$ & $9(9)$ & $9(25)$ & 0.016 \\
\hline $\mathrm{RCA}$ & $33(33)$ & $13(36)$ & 0.763 \\
\hline \multicolumn{4}{|l|}{ Basal TIMI grade } \\
\hline 0 & $60(61)$ & $28(78)$ & 0.102 \\
\hline 1 & $15(15)$ & $5(14)$ & \\
\hline 2 & $24(24)$ & $3(8)$ & \\
\hline \multicolumn{4}{|l|}{ Basal thrombus grade } \\
\hline 1 & $9(9)$ & $3(8)$ & 0.658 \\
\hline 2 & $18(18)$ & $7(19)$ & \\
\hline 3 & $18(18)$ & $6(17)$ & \\
\hline 4 & $33(33)$ & $16(44)$ & \\
\hline 5 & $21(21)$ & $4(11)$ & \\
\hline Glycoprotein IIb/IIIa use & $33(33)$ & $21(58)$ & 0.009 \\
\hline Thrombus aspiration & $12(12)$ & $10(28)$ & 0.029 \\
\hline \multicolumn{4}{|l|}{ TIMI grade post-PCI } \\
\hline 0 & $1(1)$ & $2(6)$ & 0.092 \\
\hline 1 & $2(2)$ & $3(8)$ & \\
\hline 2 & $30(30)$ & $7(19)$ & \\
\hline 3 & $66(67)$ & $24(67)$ & \\
\hline \multicolumn{4}{|l|}{ MBG post-PCI } \\
\hline 0 & $2(2)$ & $3(8)$ & 0.074 \\
\hline 1 & $22(22)$ & $4(11)$ & \\
\hline 2 & $27(27)$ & $6(17)$ & \\
\hline 3 & $48(48)$ & $23(64)$ & \\
\hline
\end{tabular}

CX: Circumflex, LAD: Left anterior descending, MBG: Myocardial blush grade, PCI: Percutaneous coronary intervention, RCA: Right coronary artery TIMI: Thrombolysis in myocardial infarction, COVID-19: Coronavirus disease-19

A combination of COVID-19 disease severity and MI might lead to cardiogenic shock. In this context, COVID patients were more commonly in shock and having mortality in our study. In accordance with our study, a previous study also demonstrated higher mortality in COVID-19 STEMI patients.

In our study, door to balloon time was within the recommended range according to the guidelines. ${ }^{[4]}$ However, it was shorter in COVID-19 patients than in those with COVID-19 negative. During the COVID-19 pandemic, majority of COVID-19 patients with lung infiltration were hospitalized. Those patients were believed to develop MI during the hospital stay. Therefore, it was easier to rush COVID-19-positive patients to the catheterization laboratory. Furthermore, COVID-negative patients with chest pain might have reluctance and fear to admit hospitals, and also, the overwhelming condition of hospitals, lack of facilities, and medical services for COVID-negative patients might be the determinant factors for high mortality and door to balloon time difference. Given the retrospective nature of this study, we could not obtain the time of symptom onset to the first medical contact of the study population.

\section{Limitations of the study}

The study population was collected from different centers. Therefore, we could not exclude the operator effect on hospital outcomes. Besides, routine PCR tests were not performed unless patients had COVID-19-related symptoms. There was a possibility that some asymptomatic patients for COVID-19 might be included in the COVID-19-positive group.

\section{Conclusion}

The development of STEMI on COVID-19 infection is much more increase in mortality and cardiogenic shock compared to the non-COVID-19 STEMI. COVID-19-associated factors such as high inflammatory activity and lung infiltration may have a deleterious prognosis in STEMI.

\section{Financial support and sponsorship}

Nil.

\section{Conflicts of interest}

There are no conflicts of interest.

\section{References}

1. Levi M, Thachil J, Iba T, Levy JH. Coagulation abnormalities and thrombosis in patients with COVID-19. Lancet Haematol 2020;7:e438-40.

2. Bikdeli B, Madhavan MV, Jimenez D, Chuich T, Dreyfus I, Driggin E, et al. COVID-19 and thrombotic or thromboembolic disease: Implications for prevention, antithrombotic therapy, and follow-up. 
J Am Coll Cardiol 2020;75:2950-73.

3. Thygesen K, Alpert JS, Jaffe AS, Chaitman BR, Bax JJ, Morrow DA, et al. Fourth Universal Definition of Myocardial Infarction; Executive Group on behalf of the Joint European Society of Cardiology (ESC)/American College of Cardiology (ACC)/American Heart Association (AHA)/ World Heart Federation (WHF) Task Force for the Universal Definition of Myocardial Infarction. J Am Coll Cardiol 2018;72:2231-64.

4. Ibanez B, James S, Agewall S, Antunes MJ. 2017 ESC Guidelines for the management of acute myocardial infarction in patients presenting with ST-segment elevation. Kardiol Pol 2018;76:229-313.

5. TIMI Study Group. The Thrombolysis in Myocardial Infarction (TIMI) trial. Phase I findings. N Engl J Med 19854;312:932-6.

6. Chesebro JH, Knatterud G, Roberts R, Borer J, Cohen LS, Dalen J, et al. Thrombolysis in Myocardial Infarction (TIMI) Trial, Phase I: A comparison between intravenous tissue plasminogen activator and intravenous streptokinase. Clinical findings through hospital discharge. Circulation 1987;76:142-54.

7. Sianos G, Papafaklis MI, Serruys PW. Angiographic thrombus burden classification in patients with ST-segment elevation myocardial infarction treated with percutaneous coronary intervention. J Invasive Cardiol 2010;22:6B-14B.

8. van 't Hof AW, Liem A, Suryapranata H, Hoorntje JC, de Boer MJ, Zijlstra F. Angiographic assessment of myocardial reperfusion in patients treated with primary angioplasty for acute myocardial infarction: Myocardial blush grade. Zwolle Myocardial Infarction Study Group. Circulation 1998;97:2302-6.

9. Williams B, Mancia G, Spiering W, Agabiti Rosei E, Azizi M, Burnier M, et al. $2018 \mathrm{ESC} / \mathrm{ESH}$ Guidelines for the management of arterial hypertension. Eur Heart J 2018;39:3021-104.

10. Cosentino F, Grant PJ, Aboyans V, Bailey CJ, Ceriello A, Delgado V, et al. ESC Scientific Document Group 2019 ESC Guidelines on diabetes, prediabetes, and cardiovascular diseases developed in collaboration with the EASD. Eur Heart J 2020;41:255-323.

11. Mach F, Baigent C, Catapano AL, Koskinas KC, Casula M, Badimon L, et al. 2019 ESC/EAS Guidelines for the management of dyslipidaemias: Lipid modification to reduce cardiovascular risk. Eur Heart J 2020;41:111-88

12. Levey AS, Eckardt KU, Tsukamoto Y, Levin A, Coresh J, Rossert J, et al. Definition and classification of chronic kidney disease: a position statement from Kidney Disease: Improving Global Outcomes (KDIGO). Kidney Int 2005;67:2089-100.

13. Xiang D, Huo Y, Ge J. Expert consensus on operating procedures at chest pain centers in China during the coronavirus infectious disease-19 epidemic. Cardiol Plus 2020;5:21-32.

14. Bangalore S, Sharma A, Slotwiner A, Yatskar L, Harari R, Shah B, et al. ST-Segment elevation in patients with COVID-19-A case series. N Engl J Med 2020;382:2478-80.

15. Choudry FA, Hamshere SM, Rathod KS, Akhtar MM, Archbold RA, Guttmann OP, et al. High thrombus burden in patients with COVID-19 presenting with ST-Segment Elevation myocardial infarction. J Am Coll Cardiol 2020;76:1168-76.

16. Leor OR, Alvarez AB, de Prado AP, Rossello X, Ojeda S, Serrador A, et al. In-hospital outcomes of COVID-19 ST-elevation myocardial infarction patients. Euro Interv 2021;16:1426-33.

17. Masi P, Hékimian G, Lejeune M, Chommeloux J, Desnos C, Pineton De Chambrun M, et al. Systemic inflammatory response syndrome is a major contributor to COVID-19-associated coagulopathy: Insights from a prospective, single-center cohort study. Circulation 2020;142:611-4

18. Zhou F, Yu T, Du R, Fan G, Liu Y, Liu Z, et al. Clinical course and risk factors for mortality of adult inpatients with COVID-19 in Wuhan, China: A retrospective cohort study. Lancet 2020;395:1054-62. 